\title{
SOUNDCSAPE AND THE UNDERSTANDING OF HISTORIC DISTRICTS IN BANDUNG
}

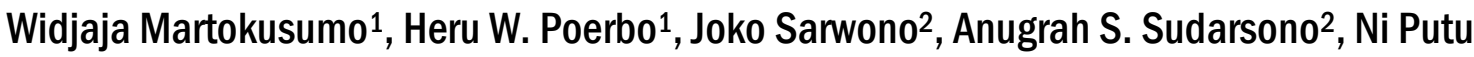 \\ Amanda Nitidara ${ }^{2}$, Michael Isnaeni Djomantoro ${ }^{1}$, Amanda Arifiana ${ }^{1}$, Feysa A. Poetry ${ }^{1}$
}

Diterima: March $8^{\text {th }} 2019$ Disetujui: May 25 2019

\begin{abstract}
According to UNESCO Convention 1972, cultural heritage consists of tangible and intangible heritage. Soundscape has been considered as a part of the intangible heritage, and it refers to the perceptual quality. In the realm of built environment, perceptual qualities become important concerns, since cultural heritage cannot be described and appreciated using monosensorial analysis fundamentally based on vision. As perceptual construct, soundscape has been considered as a new approach in understanding the formation and design of sensitive urban environment. It is argued that perceptual quality, besides visual aesthetics, geographic, psychological and socio-cultural aspects, must be part of the considerations in architecture and urban design. Bandung is well-known for its urban heritage, and as former well-designed colonial town, the historic buildings and areas have morphologically constituted the structure of the inner city. However, the modernization and globalization have led to inevitable transformations, including the destruction of historic places and fabric/district of cultural significance. With the latest urban dynamics, urban environment has also experienced an inescapable process of "sound globalization", which led to the losing of specific sound-marks in the respective area. This paper is based upon an ongoing research project on strategy for conservation of historic urban areas using soundscape approach. Methodologically, through sound walks, surveys and interviews, several notions relating to urban spatial and formal quality have been collected, assessed and interpreted. The result stands for the understanding of perceptual aspects and quality of urban space in historic urban areas that may contribute to the heritage conservation strategy.
\end{abstract}

Keywords: soundscape, sound-walk, heritage conservation strategy, Bandung

\section{INTRODUCTION}

According to UNESCO Convention 1972, cultural heritage consists of tangible and intangible heritage. Soundscape has been considered as a part of the intangible heritage, and it refers to the perceptual quality. In the realm of built environment, perceptual qualities become important concerns, since cultural heritage cannot be described and appreciated using mono-sensorial analysis fundamentally based on vision. Nowadays, questions have critically been raised in regard to the domination of visual perception in the design of built environment. Perceptual qualities propose and open a broader perspective that full spectrum of perceptual phenomena, such as sound/audition, smells/olfaction, touch/somatosensation, taste/gustation, must seriously be taken into account beyond the hegemony of visual aspect. As perceptual construct, soundscape has been considered as a

\footnotetext{
${ }^{1}$ School of Architecture, Planning and Policy Development, Institut Teknologi Bandung

${ }^{2}$ Faculty of Industrial Engineering, Institut Teknologi Bandung
} 
new approach in understanding the formation and design of sensitive urban environment, eventually historic urban districts.

The term soundscape signifies a sonic environment, formed within a context, as it is experienced and perceived by a person and people. As a perceptual construct, it encompasses various fields of practice, diverse approaches and multidisciplinary interests. The concept of 'soundscape' is originally rooted in the music and acoustic ecology research areas. It quickly expanded to other disciplines, such as acoustics, architecture, environmental health, psychology, sociology and urban studies, claiming for further attention and a holistic approach to the way we conceive the sound around us and its perception. To some extent, all the earlier mentioned disciplines have something in common. They deal with how humans experience the environments and try to establish relationships between the physical world and how the human response to it.

Research in the newly emerging topic, soundscape, relates to many disciplines including acoustics, aesthetics, anthropology, architecture, ecology, ethnology, communication, design, human geography, information, landscape, law, linguistics, literature, media arts, medicine, musicology, noise control engineering, philosophy, pedagogics, psychology, political science, religious studies, sociology, technology and urban planning. Today, soundscape is one of the main areas of acoustics, complemented with architecture, urban planning, urban design, psychology, sociology and many other disciplines as integral parts of multidisciplinary soundscape research throughout the world. The importance of such topic related to architecture, landscape, urban planning and design of built environment is the understanding that people are (the new) actors and not just observers in such engagement. This is important if one considers that there are more possibilities in tackling any problem within the calculated bottom-up strategy in managing our built environment.

As previously mentioned, perceptual qualities become important concerns since cultural heritage cannot be described and appreciated using mono-sensorial analysis fundamentally based on vision. As a perceptual construct, soundscape has been considered as the new approach in understanding the formation and design of sensitive urban environment. It is argued that perceptual quality, besides visual aesthetics, geographic, psychological and socio-cultural aspects, must be the part of the considerations in architecture, landscape, urban planning and design. This, however, has always been overlooked and left behind.

Bandung is well-known for its urban heritage, and as former well-designed colonial town, the historic buildings and areas have morphologically constituted the structure of the inner city. However, the modernization and globalization have led to inevitable transformations, including the destruction of historic places and the fabric/district of cultural significance. With the latest urban dynamics, urban environment has also experienced an inescapable process of "sound globalization", which led to the losing of specific sound-marks in the respective areas. This paper is based upon an ongoing research project on strategy for conservation of historic urban areas using soundscape approach. The research stands for the understanding of perceptual aspects and quality of urban space in historic urban areas that may contribute to the urban heritage conservation strategy. Thus, strategy of conservation can be derived from the result of how people perceived the urban quality, regardless the visual aesthetics. Last but not least, this article will put forward a further contention that perceived urban quality underlines the importance of perceptual quality (or multi sensorial approach); a new urbanism based upon the "sense of the city", which must be understood, experienced and perceived by the people in a certain context. 


\section{METHOD}

The perceptual quality, as argued, besides geographic, psychological and sociocultural, is regarded as one of important considerations in architecture, landscape, urban planning and design. For this purpose, this soundscape research tried to identify several aspects associated with or related to the architectural and design quality that would significantly contribute to the emotional attachment of a community to the chosen urban areas. Generally, the methodology used for this research was developed after methods and tools created by Aletta et al. (2016), as shown in figure 1. Questionnaires, semantic scales, observation protocol and interview protocol are the common tools. For the first stage of this research, however, questionnaires and observation protocol had been applied. The semantic scales and interview protocol through memory recalling would still be carried out to gain complete and comprehensive insights of the area in the second stage.

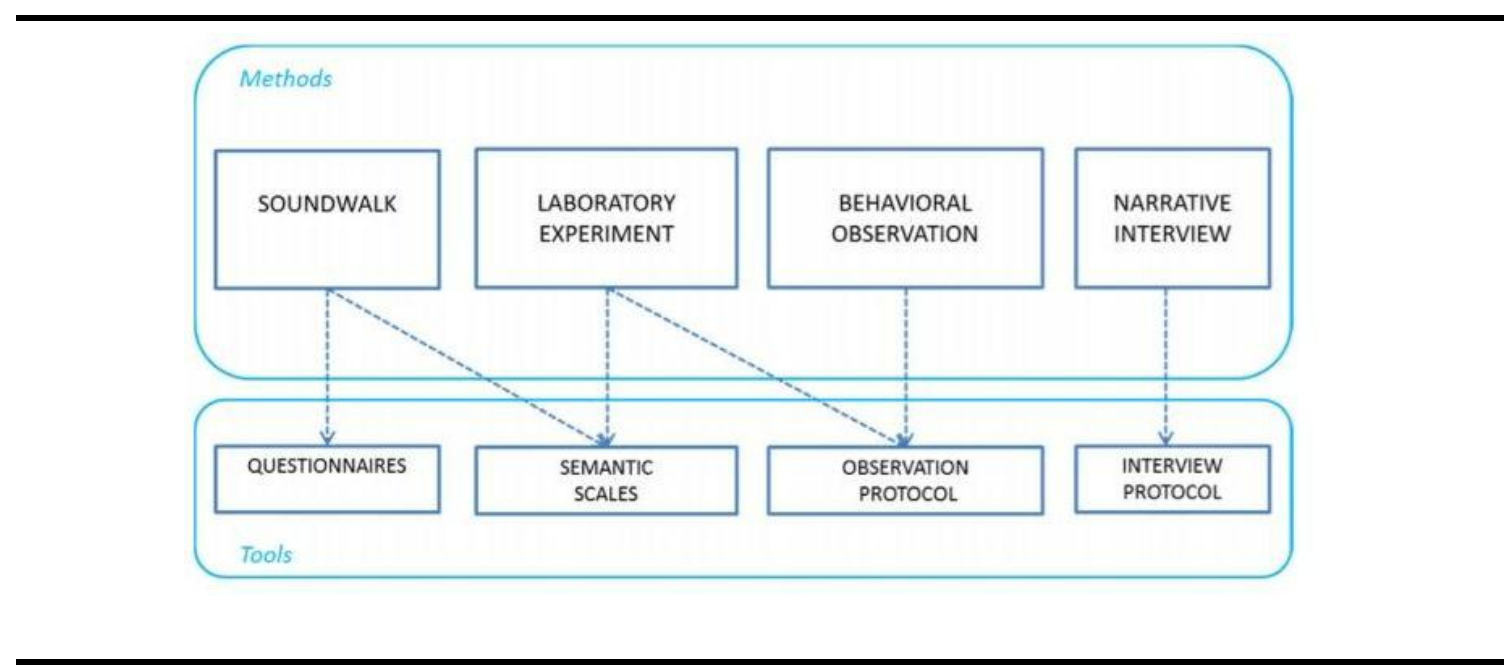

Figure 1. Methods and Research tools. Adapted from Aletta et al., 2016

For this purpose, four historic districts of the inner city of Bandung were chosen as follow: Alun-alun/the main urban square, Bank JABAR square and the Centre Point crossing (both are situated to Braga Street corridor) and the Municipality Park. In brief, there are two urban design elements, i.e. urban street corridor and urban node. The soundwalk began from the Alun-Alun and ended in the Municipality Park along Braga Street, as illustrated in figure 2. Thus, participants visited the urban square, listened at least three minutes to the acoustical environment and filled out an evaluation sheet. Sound recording was recorded at the same time for five minutes and the noise data was measured from the sound recording.

The primary data were conducted through surveys and direct observations involving 40 students from Architecture, Urban Design and Buildings Physics, including the research team. The participants were kindly asked to do soundwalks and fill semi-structured online questionnaire, which consists of questions on human sensory like: What does the participant feel? What sound(s) can be identified? Are any there positive and disturbing sound(s) in this area? Can you identify the visual element(s)? Are any there positive and negative visual element(s) in this area? Can you identify the smell(s) of this area? Are there any positive and negative smell(s) in this area? How is the thermal condition in this area? Are there iconic sound(s) in this area? What is the ideal condition in this area? How was the condition of this area in the past? 

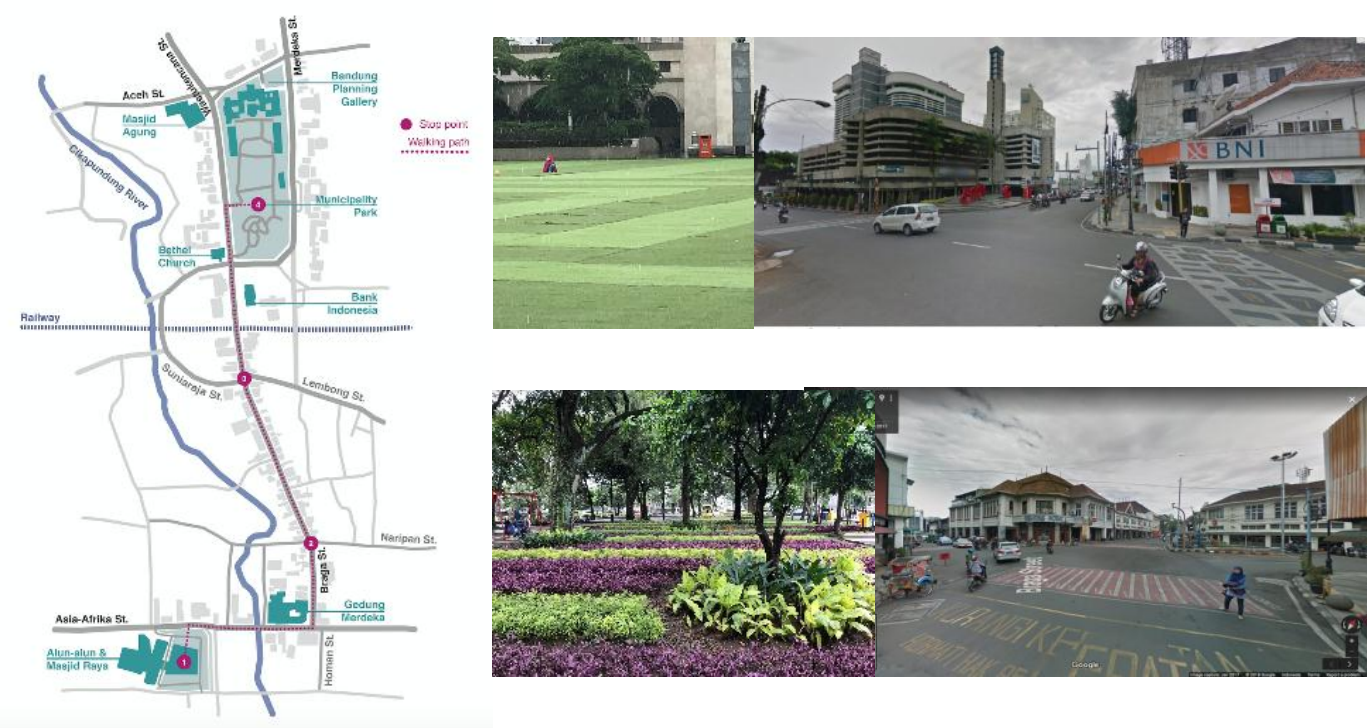

Source: Redrawn by Poetry 2018 (left) and Documentation Arifiana, 2018

Figure 2. The route of soundwalk and the chosen four nodes

For the first stage of research, the focus was limited to the auditory, olfactory and visual perception. The questionnaires or evaluation sheets were distributed to the participants via online prior to the soundwalks. After the data had been collected through soundwalks and direct observations, content and cluster analysis were carried out to analyze and interpret; thus, it dealt with a text analysis. Visual analyses were conducted based on the paperless semi-structured questionnaires, the observation, and the documentation of four chosen observation locations. Another questionnaire in form of a semantic scale was also performed, and the data were used for the second stage of research together with the data collected from interviews. The result in the first stage was still compared with the interviews with local experts, academcians, and historic preservationists to gain a complete process of data collecting.

\section{RESULT AND DISCUSSION}

\section{Analysis}

\section{Alun-Alun}

As a traditional urban element in Java, an urban square is surrounded by important traditional structures, such as Regent (mayor's) house with its Pendopo, grand mosque and commercial uses. In the past, Alun-alun was a meeting point between rulers and his/her disciples, and it also catered important events, as illustrated in figure 3 and figure 4 . Alunalun has recently been rehabilitated, upgraded, and transformed in 2016 into a modern public open space, with artificial greenery. This beautification effort is highly appreciated by people of Bandung despite some technical issues of the artificial grass. The square is chosen by the locals as an interesting public space, especially at the weekends and holidays. It serves as a family recreation spot in the inner-city of Bandung, and it has become of the most frequently visited places.

Through direct observation, despite the disturbing roar of vehicles and the polluted air, this Alun-alun provides a place where people can meet and have family recreation, especially for children; hence an appropriate place for social interactions. Visually, this area 
is dominated by the grand mosque, the commercial buildings, and colonial office buildings with the influence of art-deco style. Moreover, as the part of the traditional urban core, the Mayor's house, the mosque and also the twin minaret of the grand mosque are then open for public in order to give more attractions for visitors of Alun-alun. From the questionnaires, it can be concluded that this place is perceived and considered as the best place for the well-being of the participants, the place that is visually attractive and pedestrian friendly, and the place that has a good ambience.

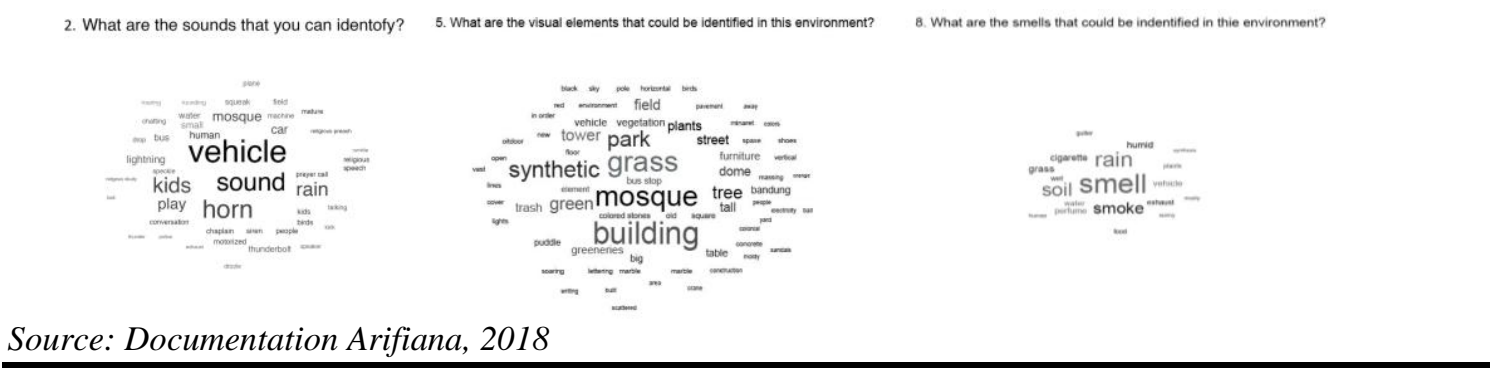

Figure 3. Alun-alun

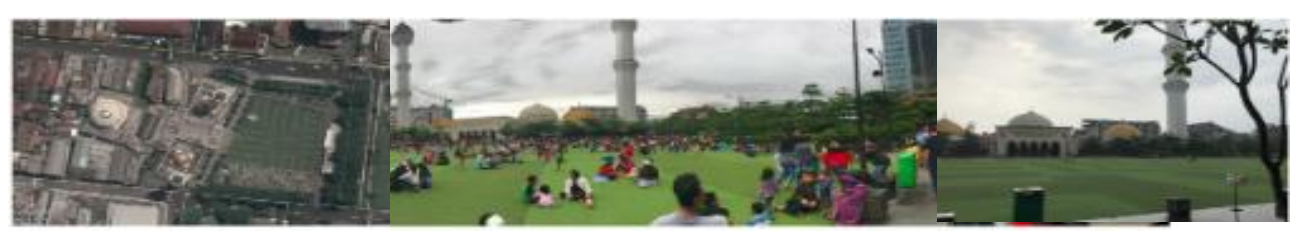

Source: Documentation Arifiana, 2018

Figure 4. Word Mining from hearing, seeing and smelling at Alun-alun

\section{Bank JABAR Square}

This square is located at the intersection between Braga Street and ABC Street. The square was built around three years ago, as a part of the beautification of Braga Street corridor. The square is surrounded by old colonial buildings that extend along the Braga Street corridor adjacent to retails and banks. The building of Bank JABAR was originally called Denis (De eerste Nederlandsch Indisch Sparkasse) Bank building. This bank was designed by a Dutch, A.F. Aalbers in 1935 with its square was used as parking lot for customers. Since the street beautification program, Bank JABAR Square is constructed with the purpose of increasing public spaces and pedestrian activities at the corridor.

Through direct observation, the square is actually lack of several aspects to support pedestrian activities. The questionnaires explore few elements including the architectural condition where the historic buildings received very little attention and are less maintained. Street vegetation is minimal with too many billboard signage and electric cables hanging in disarray. These problems certainly influence the ambiance for the street corridor environment and make it vulnerable to climate exposure. Since the square is located at figure 6).

intersections of two major streets, the traffic of vehicle is still dominant. (figure 5 and 

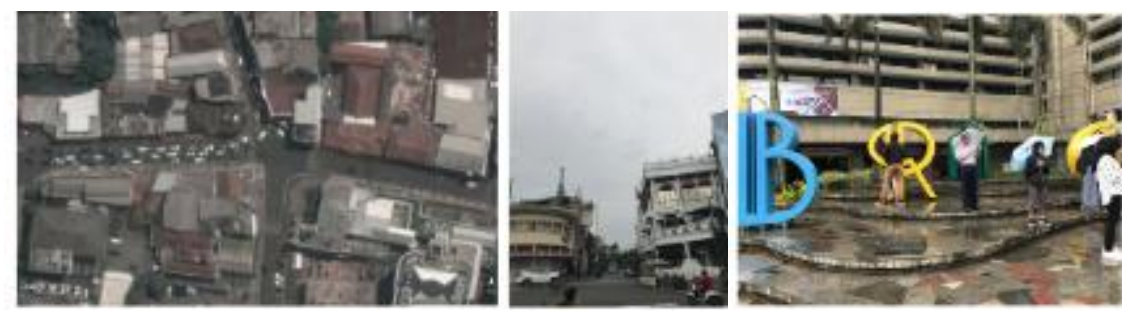

Source: Documentation Arifiana, 2018

Figure 5: Bank JABAR Square
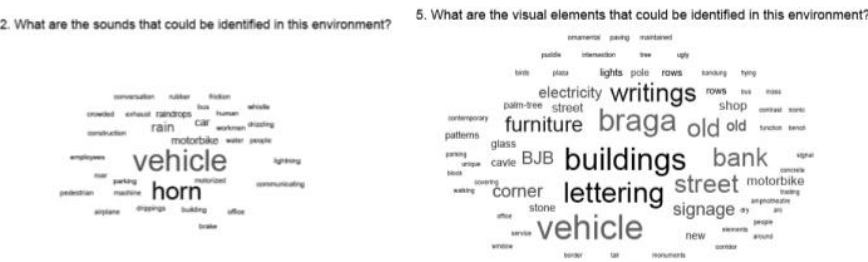

8. What are the smells that could be idenethed in this environment?

Figure 6. Word Mining for hearing, seeing and smelling at Bank JABAR Square, 2018

\section{Centre Point Crossing}

This node is located in the north end of Braga Street, in which it changes direction and also intersects with two other one-way streets, making the crossing extremely busy in terms of traffic. Along the way from point two (Bank JABAR Square) to this point, lies the most famous fragment of Braga corridor where retails and hospitality businesses are situated. This view has existed since 1884 when a grocery store opened its outlet here; triggering establishment of cafes, restaurants, and hotels, soon transformed this part of Braga Street into the most important Dutch Indies shopping promenade in the early twentieth century, as illustrated in figure 7 and figure 8.
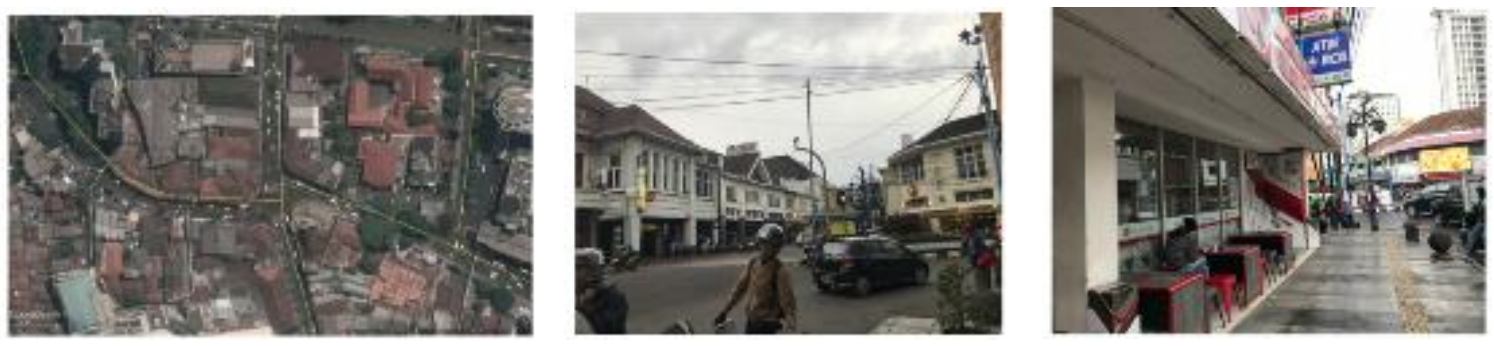

Source: Documentation Arifiana, 2018

\section{Figure 7. The Centre Point Crossing}

Today, this promenade is highly engaged with pedestrians, and it offers typical old town scenery with fairly maintained historic buildings turned into an eye candy. The notion of exploring the area by walking becomes important because this way during the soundwalk, the words "people" and "chat" popped up as what might be perceived as a 
positive sound. The other findings The other distinctive findings from point two (mostly dominated by sounds of vehicles) are "café" and "music". This observation, again, came from a close interaction between pedestrians and their surroundings; so close that they could hear the sounds coming out from individual interiors at the sidewalk. Although there are quite a lot of negative notes in the visual aspects, such as overlapping signage, untidy installation of electricity cables, and out-of-context facades, the existing vehicles still seem to be bothering the most since it is heavily listed as negative in every aspect (of auditory, olfactory and visual perception) in the questionnaire, especially at the way leading to the crossing where the traffic becomes even more chaotic and pedestrians start losing direction.

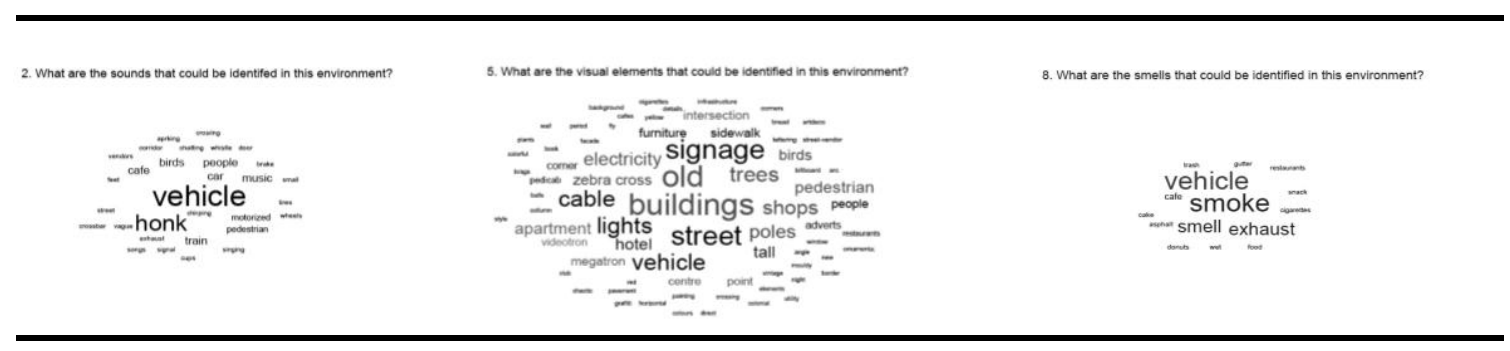

Figure 8. Word Mining for hearing, seeing and smelling at the Centre Point Crossing, 2018

\section{Municipality Park}

As one of the important urban parks in Bandung, the Municipality Park ( Taman Balai Kota) in early of 19th century was the part of the coffee warehouse owned by a land lord, Andreas de Wilde. After the municipality building (architect E.R de Roo) was built in 1935, the park was then named "Pieter Stiejhof", a former assistant of Priangan regent. The whole park consists of several thematic parks, such as Historical Park, Labyrinth Park, Rhinos Park and Dewi Sartika Park, which offer many interesting experiences for public. The efforts to improve the quality of the open spaces and urban parks are significant, but they do not increase the quantity of the greenery. This park is the part of the green open space system in Bandung, which is considered critical, since the number of green areas in Bandung is decreasing due to recent urban dynamics. According to recent data from the municipality office, the recorded number of open space is $12.15 \%$ from the total area, but there has been another claim that the real percentage is only $8 \%$.

From direct observation, it is known that the park serves as an interesting place. This park is also the part of the beautification projects that has been conducted since 2016. The park has been well-furnished with amenities and ambience. The park offers as an urban oasis, and comparing to other three locations, this is the friendliest pedestrian park with shade of trees and facilities related to leisure time. The roar of vehicles can still be heard, but overall the participants feel the tranquility, breezes; and sounds from trees movement, birds chirping, gurgling water from the fountain and from people/children. All the participants agreed that audially the disturbance was insignificant while regarding the olfactory sense; the smells of plants/nature were dominant. The participant also concluded that the location was visually pleasant, and the whole ambience was relaxing, as illustrated in figure 9 and figure 10. 

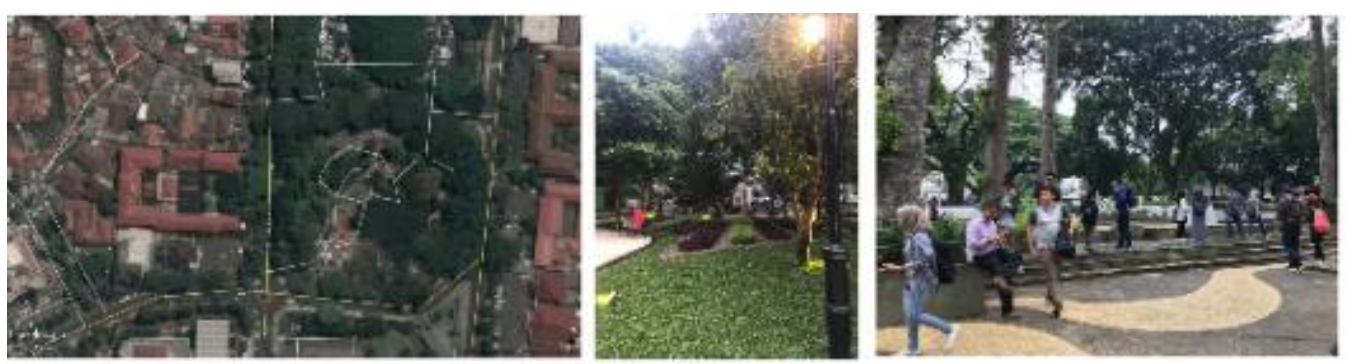

Source: Documentation Arifiana, 2018

Figure 9. The Municipality Park

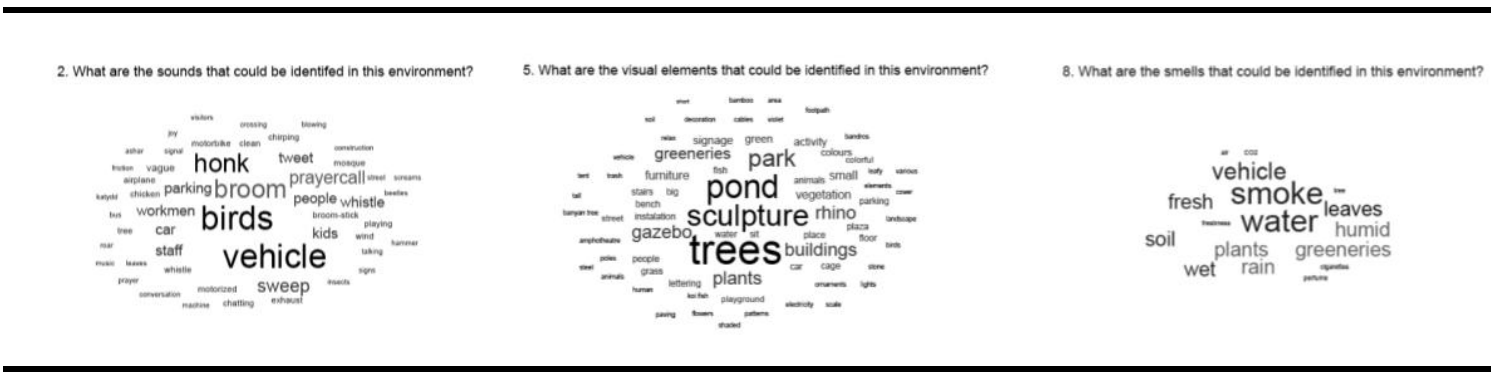

Figure 10. Word Mining for hearing, seeing and smelling at the Municipality Park, 2018

\section{Discussion}

The soundwalks and data collection were conducted two times, with time difference approximately one month. Weather condition in the first trail was cloudy while the second drizzly. The specific characteristics of the objects. According to the analysis and interpretation, two categories in regard to the common quality of the character can be identified as follows: Alun-Alun and Municipality Park have the same characteristics while the Bank JABAR square the Centre Point crossing share a similar character, as illustrated in Table 1 and Figure 11. The noise levels in these areas still comply with the noise standard for recreational area in Indonesia (KEPMENLH no. 48/1996). The second and the third locations are situated along the Braga Street and share the same characteristics in term of morphological structure; that is, as the part of the urban corridor. Alun-alun and the Municipality Park are both perceived and considered as the best place for the well-being participants, visually attractive and pedestrian friendly with good ambience. On the contrary, the Braga Street corridor, which actually is the locus of historic buildings with extraordinary architectural styles, is negatively appreciated since the corridor is crowded with vehicles, and to some extent the newly rehabilitated sidewalk is not always pedestrian friendly as well as polluted in terms of visual, audial and olfactory sense.

The activities in the entire historic spaces seem not to be affected by the overall noise level. People still come to the Braga corridor although the sound level is higher than the other locations. They also feel comfortable doing their activity there. Observation showed that the activities done in Alun-Alun and Municipality Park were different than the ones in the Braga corridor. Thus, such phenomena indicate that noise measurement cannot be used to predict the people's comfort in a certain place. More comprehensive approach, which includes people's perception and expectation, needs to be done to understand the historic district. 
Table 1. Noise profile (dBA) at four observation locations

\begin{tabular}{lllrlrlr}
\hline Alun-Alun & dBA & Bank JABAR & dBA & Centre Point & dBA & Taman Balai Kota & \multicolumn{1}{c}{ dBA } \\
\hline Leq & 66,03 & Leq & 69,29 & Leq & 71,19 & Leq & 67,46 \\
L10 & 68,59 & L10 & 72,02 & L10 & 72,262 & L10 & 69,878 \\
L50 & 64,44 & L50 & 66,74 & L50 & 67,8 & L50 & 64,13 \\
L90 & 61,34 & L90 & 62,33 & L90 & 64,8 & L90 & 60,9 \\
\hline
\end{tabular}

\section{Noise profile}

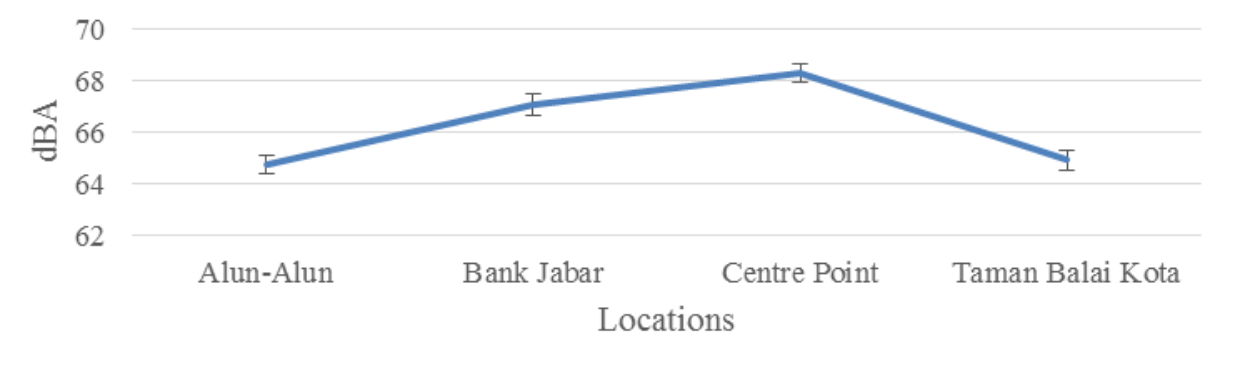

Figure 11. The Measurement of Noise Profile at Four Observation Locations

Regarding the visual aesthetics, some positive visual aspects have strong connection with the urban quality which give contribution through its urban elements; such as, historic buildings/architecture, spaces, greenery (trees and planting box), details of heritage buildings close to both areas, and amenities; while negative aspects are represented by huge billboards/signage, electricity/infrastructure poles and the physical quality of sidewalks. In addition to this, the sidewalk at certain locations was not well-designed and properly maintained. Though some routes of sidewalk have already been repaired with barrier free design principles, in many cases the new bollards and amenities on the sidewalks negatively affect the movement of pedestrians.

Roar of vehicles is audially considered disturbing in both places, and it affects the comfort of pedestrians while the scent of trees, wet ground and the less intensive aroma of food are positively perceived. This phenomenon also unveils that both locations are burdened with heavy traffics almost during the time of observations. On the other hand, the participants agreed that the sounds of people/children, adzan/calls for praying, music, breezes and trees were audially preferable. Regarding to the olfactory sense, participants also agreed that polluted air, mostly caused by vehicle exhaust and cigarette smoke, were considered dominantly annoyed in both areas.

\section{CONCLUSION}

This paper has revealed the importance of the soundscape approach in the realm of architecture, urban design, and heritage conservation. It also unveils the nexus of how this newly emerging topic has more possibilities to contribute to the development strategy for heritage conservation. Through experiments, it can be concluded that strategy of urban (heritage) conservation can be derived from the result in how people perceive the urban quality, regardless the visual aesthetics. This article puts forward the argument that perceived urban quality underlines the importance of perceptual quality (or multi sensorial approach); a new urbanism based upon the "sense of the city" which must be understood, experienced and perceived by the people in a certain context. Thus, based on the findings, 
soundscape approach offers potential possibilities for many new researches in relation to architecture, landscape architecture, urban planning and design that will improve the urban quality with special character, particularly the ones related to urban historic districts.

\section{ACKNOWLEDGEMENT}

The paper is based on the ongoing research project on Soundscape as a Strategy of Urban Heritage Conservation, and it was financially funded through ITB Research Grant 2018. The research was jointly organized and conducted by the Architectural Design Research Group, the School of Architecture, the Planning, Policy Development and Building Physics Research Group, and the Faculty of Industrial Engineering in Institut Teknologi Bandung.

\section{REFERENCES}

Aletta F, Kang J, Axelsson Ö. (2016). Soundscape descriptors and a conceptual framework for developing predictive soundscape models. Landscape and Urban Planning 149, p: 65-74.

Botteldooren D, Lavandier C, Preis A, Dubois D, Aspuru I, Guastavino C, Brown L, Nilsson M, Andringa T C. (2011). Understanding urban and natural soundscapes. FORUM ACUSTICUM. Aalborg.

Casidy T. 1997. Environmental Psychology, London: Psychology Press.

Domitrović H, Jambrošić K, Horvat M, Filipan K, Kang J, Jin H, Zhao W, Wu H. (2016). Soundscape as Heritage - How Important is it? Evaluation of Soundscape in China and Croatia. EuroRegio. Porto. p: 18.

Farina A, Buscaino G, Ceraulo M, Pieretti N. (2014). The Soundscape Approach for the Assessment and Conservation of Mediterania Landscapes: Principles and Case Studies. Journal of Landscape Ecology 7 , p: 10 - 22.

Kang J. (2007). Urban Sound Environment. London: Taylor \& Francis.

Kang J, Aletta F, Gjestland T T, Brown L A, Botteldooren D, Schulte-Fortkamp B, Lercher P, van Kamp I, Genuit K, Fiebig A, Coelho L B, Maffei L, Lavia L. (2016). Ten Question on the Soundscape of the Built Environment. Building Environment 108, p: 284-294.

Keputusan Menteri Negara Lingkungan Hidup No. KEP-48/MENLH/11/1996 tentang Baku Tingkat Kebisingan (standard noise level).

Maffei L. (2010). Soundscape approach in urban renewal: parks and areas of acoustic quality. DAGA. Berlin. p: 51-52.

Martokusumo W, Poerbo H W, Koerniawan M D, Krisanti S H. (2017). Algae and building façade revisited. a study of façade system for infill design. Journal of Architecture and Urbanism 41, p: 296 - 304.

Peraturan Walikota (mayor decree) Bandung No. 921 Tahun 2010 tentang Pelaksanaan Peraturan

Daerah Kota Bandung No. 19 Tahun 2009 tentang Pengelolaan Kawasan dan Bangunan Cagar Budaya. Bandung, 2010.

Riza M, Doratli N. (2015). The critical lacuna between new contextually juxtaposed and freestyle buildings in historic settings. Journal of Architectural and Planning Research 32, p: 234 - 257.

Schafer R. (1977). The Tuning of the World, New York: Knopf.

Shirvani H. (1985). The Urban Design Process. Michigan: Van Nostrand Reinhold.

Sörqvist P. (2016). Grand Challenges in Environmental Psychology. Frontiers in Psychology.

Tiesdell S, Oc T, Heath T. (1996). Revitalizing Historic Urban Quarters, Oxford: Architectural Press

TruaxB. (1978). Handbook for Acoustic Ecology, Vancouver: ARC Publication.

UNESCO. (2005). Basic text of the 1972 World Heritage Convention. UNESCO World Heritage Centre. Paris. 